\title{
ENSAIO SOBRE A EDUCAÇÃO A DISTÂNCIA NO BRASIL
}

\author{
Maria Luiza Belloni*
}

\begin{abstract}
RESUMO: O texto analisa a educação a distância no Brasil, buscando estabelecer os nexos teóricos e práticos entre duas dimensões essenciais da questão: as injunções políticas que determinam as práticas experimentadas nas diversas experiências realizadas e as questões econômicas que se revelam nas tecnologias utilizadas e nas formas como estas se articulam com as condições reais de implementação. A análise está baseada em dados de pesquisas empíricas realizadas em diferentes momentos da história recente do Brasil, com destaque em experiências de formação de professores, no estudo das quais a ênfase é dada na análise das formas de apropriação e de aproveitamento das propostas de educação a distância pelos usuários e nas contradições entre as promessas de um discurso tecnocrático que prioriza a técnica e a realidade dos sistemas de ensino que não conseguem assegurar condições mínimas de realização das propostas.

Palavras-chave: Comunicação educacional. Educação a distância. Tecnologia educacional. Tecnologias de informação e comunicação. Formação de professores.
\end{abstract}

\section{ESSAY ABOUT DISTANCE EDUCATION IN BRAZIL}

ABSTRACT: This text analyzes distance education in Brazil in order to establish the theoretical and practical links between two of its essential dimensions: The political injunctions that determine the practices tested in various experiments under way; and the economical issues that emerge from the technologies used and how they articulate to the real conditions of implementation. The analysis is based on data from empirical research conducted at different moments of Brazilian recent history, with an emphasis on teacher training experiments. Emphasis is given to the analysis of the forms of appropriation and use of the distance education proposals by users. The contradictions between the promises of a technocratic discourse, which gives priority to technique, and the reality of the teaching systems, which are not able to guarantee the basic conditions to accomplish the proposals, is also highlighted.

Key words: Educational communication. Distance education. Educational technology. Information and communication technologies. Teacher training.

* Professora da Universidade Federal de Santa Catarina (UFSC). E-mail: malu@intergate.com.br 


\section{Inovações tecnológicas e processos educacionais}

$P$

edagogia e tecnologia (entendidas como processos sociais) sempre andaram de mãos dadas: o processo de socialização das novas gerações inclui necessária e logicamente a preparação dos jovens indivíduos para o uso dos meios técnicos disponíveis na sociedade, seja o arado seja o computador. O que diferencia uma sociedade de outra e diferentes momentos históricos são as finalidades, as formas e as instituições sociais envolvidas nessa preparação, que a sociologia chama "processo de socialização".

Neste início do século 21, quando o futuro já chegou, observamos novos modos de socialização e mediações inéditas, decorrentes de artefatos técnicos extremamente sofisticados (como por exemplo a realidade virtual) que subvertem radicalmente as formas e as instituições de socialização estabelecidas: as crianças aprendem sozinhas ("autodidaxia"), lidando com máquinas "inteligentes" e "interativas", conteúdos, formas e normas que a instituição escolar, despreparada, mal equipada e desprestigiada, nem sempre aprova e raramente desenvolve. Do ponto de vista da sociologia, não há mais como contestar que as diferentes mídias eletrônicas assumem um papel cada vez mais importante no processo de socialização, ao passo que a escola (principalmente a pública) não consegue atender minimamente a demandas cada vez maiores e mais exigentes e a "academia" entrincheira-se em concepções idealistas, negligenciando os recursos técnicos, considerados como meramente instrumentais. No setor privado, as escolas respondem "naturalmente" aos apelos sedutores do mercado e se entregam de corpo e alma à inovação tecnológica, sem muita reflexão crítica e bem pouca criatividade, formando não o usuário competente e criativo, como seria desejável, mas o consumidor deslumbrado.

Cabe lembrar o óbvio, como meio de sinalizar a perspectiva desta análise: as inovações educacionais decorrentes da utilização dos mais avançados recursos técnicos para a educação (o que inclui as Tecnologias de Informação e Comunicação, TIC, mas também as técnicas de planejamento inspiradas nas teorias de sistemas, por exemplo) constituem um fenômeno social que transcende o campo da educação propriamente dita, para situar-se no nível mais geral do papel da ciência e da técnica nas sociedades industriais modernas. No capitalismo triunfante da segunda metade do século 20 , o avanço tecnológico permitiu não apenas a expansão mundial do industrialismo como também a difusão planetária de uma cultura mínima (ou "básica"), que serve de linguagem comum 
para a "comunicação publicitária”, difusora de um discurso tecnocrático que vende ilusões com argumentos científicos. A ciência e o desenvolvimento tecnológico, cujas relações ambíguas poderíamos classificar como incestuosas, adquirem em nossas sociedades contemporâneas um grau de autonomia muito importante, tornando-se as principais forças produtivas da atual fase do capitalismo (Marcuse, 1968; Lasch, 1983; Habermas, 1973; Benakouche, 2000; Belloni,1994 e 2001b).

Nos países subdesenvolvidos porém industrializados e altamente urbanizados; pobres e atrasados cultural e politicamente, mas com "bolsões tecnificados" e globalizados; nesses países as contradições e as desigualdades sociais tendem a ser agravadas pelo avanço tecnológico. São aqueles países que, tendo sido compelidos a importar os piores malefícios do desenvolvimento (poluição, devastação ecológica, concentração urbana), não puderam exigir ao mesmo tempo os benefícios (o avanço social e político) e continuam sofrendo os problemas típicos de sua situação tradicional (estrutura agrária arcaica, política oligárquica, desemprego estrutural, ignorância, exclusão e miséria), agravados de modo inédito na história pela eficácia tecnológica. Para ilustrar este agravamento pensemos, numa metáfora, na motosserra e no machado em ação na Amazônia.

As transformações na estrutura produtiva das sociedades capitalistas contemporâneas (estrutura que se convencionou descrever com base em conceitos como: "fordismo" e "pós-fordismo", "globalização" e "deslocalização", "flexibilização” [ou precarização do trabalho], "estado mínimo”, entre outros), impulsionadas pelo avanço técnico, especialmente em informática e telecomunicações, criaram novos contextos culturais ("cibercultura”, "culturas híbridas" ou simplesmente "paisagem audiovisual”, sem esquecer a "internacional publicitária”), caracterizados por um hibridismo perverso e redutor, que alguns autores consideram como uma espécie de pós-modernidade "avant la lettre", observável em alguns países da América Latina, especialmente o México (Canclini, 1998; Yúdice, 1991; Mattelart, 1994; Belloni, 1998).

A mediatização generalizada da informação tende a vulgarizar a ciência, vender gadgets tecnológicos, estabelecer e divulgar a agenda política, além de construir o imaginário coletivo com seus rituais planetários: os sucessos dos heróis esportivos e das modelos deslumbrantes, o casamento e a morte da princesa, a morte do campeão de Fórmula 1, os fiascos do presidente dos EUA, a truculência do líder árabe, entre tantos outros. A generalização do acesso à informação 
midiática tende a transformar o indivíduo em um ser mais racional e menos intuitivo, isto é, mais reflexivo. Esta reflexividade, característica típica das sociedades contemporâneas, radicalmente modernas, consiste, segundo Giddens, "no fato de que as práticas sociais são constantemente examinadas e reformadas à luz de informação renovada sobre essas próprias práticas, alterando assim constitutivamente seu caráter”. Ou seja, as práticas locais, cotidianas, tradicionais são permanentemente influenciadas pelas informações globais, baseadas numa cultura pseudocientífica.

A publicidade comercial e política constrói suas mensagens com base nesta cultura mundializada, que ela ajuda a criar e recriar constantemente, e destina-as ao indivíduo "reflexivo", típico destas sociedades globalizadas, radicalmente modernas (Giddens, 1994 e 1998; Mattelart, 1994; Belloni, 1994).

Tais transformações técnicas, econômicas e culturais geram necessariamente novos modos de perceber e de compreender o mundo: o local é reinterpretado à luz do global, o afetivo é sublimado no espetáculo e transformaram-se os modos de aprender das novas gerações, bem como suas representações sobre, e suas relações com, a instituição escolar (Debord, 1967; Lasch, 1979; Belloni, 2001a e 2001b). Tudo isso coloca, para o campo da educação, desafios imensos, tanto teóricos quanto práticos. As novas gerações estão desenvolvendo novos modos de perceber (sintéticos e "gestaltianos" em contraposição aos modos analíticos e seqüenciais trabalhados na escola), novos modos de aprender mais autônomos e assistemáticos ("autodidaxia”), voltados para a construção de um conhecimento mais ligado com a experiência concreta (real ou virtual), em contraposição à transmissão "bancária" de conhecimentos pontuais abstratos, freqüentemente praticada na escola. Se isso é verdade, então a instituição escolar corre o risco não apenas de perder terreno para os sistemas de mídias eletrônicas, como agência de socialização, mas de perder também o contato, a capacidade de se comunicar, com as novas gerações que ela deve educar (Babin, 1989; Porcher, 1974; Perriault, 1996; Belloni, 1995a; Jacquinot, 1990; Fusari, 1994).

No contexto atual do capitalismo, sobretudo com o sucesso incontestável dos sistemas midiáticos de vocação mundial (televisão e internet), o campo educacional aparece como uma nova fatia de mercado extremamente promissora, na qual o avanço técnico em telecomunicações permite uma expansão globalizada e altas taxas de retorno para investimentos privados transnacionais. Evidentemente, o modelo neoliberal selvagem, aplicado aos países periféricos segundo receitas das agências internacionais, só vem favorecer a expansão de iniciativas 
mercadológicas de larga escala, colocando nos mercados periféricos, a exemplo do que ocorre há muito no campo da comunicação, produtos educacionais de baixa qualidade a preços nem tão baixos. É aí que se abre o mercado da educação a distância, no qual o uso intensivo das TIC se combina com as técnicas de gestão e marketing, gerando formas inéditas de ensino que podem até resultar, às vezes e com sorte, em efetiva aprendizagem.

Grandes empresas transnacionais tendem a ampliar suas atividades tentando acaparar todos os setores deste mercado florescente que pode ser definido muito frouxamente como "educação latíssimo sensu", no qual se incluem produtos muito diversificados, que vão desde o entretenimento cultural e educativo (documentários, por exemplo) até cursos formais, oferecidos em vários suportes e modalidades, passando por artigos à la carte, que atendem a demandas sofisticadas, como o atendimento pedagógico oferecido a pais e professores pelo site educação.com, portal educativo muito sofisticado, do grupo francês Vivendi. Esta empresa, aliás, é um ótimo exemplo deste tipo de expansão típica do capitalismo desta passagem de século. Originalmente uma empresa privada tradicional, mas com negócios com o poder público, atuando no fornecimento de água (Lyonnaise des Eaux) este grupo foi ampliando seus ramos de atividades, investindo sistematicamente em alguns novos setores promissores da economia: publicidade e edição nos anos 70, televisão comercial nos anos 80, quando o fim do monopólio estatal na França abriu grandes possibilidades de expansão. Atualmente (2001) a Vivendi acaba de se tornar o segundo maior grupo de comunicação do mundo, tendo comprado a grande produtora Universal, de Hollywood, distribuidora de filmes, discos e toda a gama de produtos do show business americano. Maior que a Vivendi, hoje, só a America On Line, AOL, dona da CNN, Time Warner, Cartoon Network e outras gigantes das mídias.

Neste quadro de dificuldades para os países periféricos como o Brasil, as possibilidades de mudança, no sentido da democratização do acesso aos meios técnicos disponíveis na sociedade e da diminuição das desigualdades sociais, situam-se no nível das escolhas políticas da sociedade, ou seja, da capacidade de a escola e os cidadãos acreditarem e agirem conseqüentemente - em uma concepção dos processos de educação e comunicação como meios de emancipação e não apenas de dominação e exclusão (Belloni, 1995b e 2001a).

Acreditar que o usuário tem grande margem de escolha e de autonomia ante as tecnologias de informação e comunicação, como faz o 
discurso tecnocrático neoliberal do pós-fordismo, faz mais sentido como uma proposta de ação pedagógica do que como uma análise da realidade.

Buscar enfocar as possibilidades de autonomia do cidadão consumidor é válido numa perspectiva de mudança, de educação para o exercício dessa autonomia. Essas possibilidades, porém, não são oferecidas pelas novas potencialidades técnicas, que a sociotécnica tende a enfatizar, mas situam-se na capacidade política de os grupos sociais se organizarem em projetos educativos de mudança, de modo a assegurar que os sistemas educacionais de todos os níveis e modalidades sejam capazes de oferecer oportunidades de acesso a estas tecnologias, a todas as crianças e jovens. Não é a natureza mais suave e mais amigável das máquinas que permitirá a apropriação criativa dessas tecnologias, muito antes pelo contrário, estas características técnicas aumentam seu poder de sedução ante o usuário desprevenido.(Belloni, 2001b)

\section{Integração das TIC na educação}

Há muito venho trabalhando com a tese de que para entender o conceito e a prática da educação a distância é preciso refletir sobre o conceito mais amplo, que é o uso das (novas) tecnologias de informação e comunicação na educação. Pois vivemos num mundo saturado de máquinas, muitas delas fascinantes, especialmente aquelas que trabalham com as estruturas simbólicas da sociedade, produzindo mercadorias imateriais (privilégio até há pouco reservado às igrejas e a alguns artistas), que podem ser teletransportadas, sob uma forma genérica chamada "informação". Nicholas Negroponte, o diretor de um dos laboratórios de mídias mais avançados do mundo (Media Lab do MIT - Massachusetts Institute of Technology), defende, em seu livro $A$ sociedade digital (1995), a tese de que o mundo se divide em átomos e bits, aqueles carregados de materialidade, estes símbolos do novo elemento imaterial que tenderia a predominar no futuro: a informação eletrônica.

Como já foi dito, todas as mídias, as novas como as "velhas", fazem parte do universo de socialização das crianças, participando, de modo ativo e inédito na história da humanidade, da socialização das novas gerações, este processo tão complexo que transforma a criança em ser social, capaz de viver de modo competente, isto é, "sociável", em sociedade. Novos "textos" surgem na paisagem audiovisual que os jovens contemplam e aprendem, sozinhos ou com outros jovens, a ler e a interpretar. Imagens coloridas fixas e em movimento, sons ambientes, música, linguagem oral e escrita, teatro, todas estas formas de expressão 
- "linguagens" - estão mixadas numa mesma mensagem, construindo significados, carregando representações, difundindo símbolos.

Deste ponto de vista, de mixagem de linguagens novas e velhas, veiculadas em novos meios de comunicação, o eixo da discussão sobre educação a distância se desloca, passando a ser a mediatização técnica da mensagem educacional e não mais a distância física entre o sujeito aprendente e o sistema ensinante (Carmo, 1998; Trindade, 1992). A mediatização técnica, isto é, a concepção, a fabricação e o uso pedagógico de materiais multimídia, gera novos desafios para os atores envolvidos nestes processos de criação (professores, realizadores, informatas etc.), independentemente das formas de uso: o fato de que esses materiais possam vir a ser utilizados por estudantes em grupo, com professor em situação presencial (no laboratório da universidade, por exemplo), ou a distância por um estudante solitário, em qualquer lugar e em qualquer tempo, só aumenta a complexidade desses desafios. Há que considerar, como fundamento dessa mediatização, os contextos, as características e demandas diferenciadas dos estudantes que vão gerar leituras e aproveitamentos fortemente diversificados.

Aliás, o próprio conceito de distância está se transformando, como as relações de tempo e espaço, em virtude das incríveis possibilidades de comunicação a distância que as tecnologias de telecomunicações oferecem. Também o conceito de interatividade carrega em si grande ambigüidade, oscilando entre um sentido mais preciso de virtualidade técnica e um sentido mais amplo de interação entre sujeitos, mediatizada pelas máquinas. Cabe perguntar que espécie de interação pode existir entre o sistema complexo que produz o jogo na internet e seus milhões de usuários jovens espalhados pelo mundo, ou mesmo entre estes últimos?

Dentro dos limites deste trabalho não é possível aprofundar estas questões, colocadas como marcos teóricos de análise que não podemos perder de vista se quisermos compreender o fenômeno educação a distância, aqui entendido como parte de um processo de inovação educacional mais amplo que é a integração das novas tecnologias de informação e comunicação nos processos educacionais.

Essa integração, como eixo pedagógico central, pode ser uma estratégia de grande valia, desde que se considere estas técnicas como meios e não como finalidades educacionais, e que elas sejam utilizadas em suas duas dimensões indissociáveis: ao mesmo tempo como ferramentas pedagógicas extremamente ricas e proveitosas para a melhoria e a expansão do ensino e como objeto de estudo complexo e multi- 
facetado, exigindo abordagens criativas, críticas e interdisciplinares, e podendo ser um "tema transversal" de grande potencial aglutinador e mobilizador (Belloni, 2001a).

Por que é urgente integrar as TIC nos processos educacionais? A razão mais geral e a mais importante de todas é também óbvia: porque elas já estão presentes e influentes em todas as esferas da vida social, cabendo à escola, especialmente à escola pública, atuar no sentido de compensar as terríveis desigualdades sociais e regionais que o acesso desigual a estas máquinas está gerando.

Quanto à educação a distância, o conceito tende a se transformar, pois uma das macrotendências que se pode vislumbrar no futuro próximo do campo educacional é uma "convergência de paradigmas" que unificará o ensino presencial e a distância, em formas novas e diversificadas que incluirão um uso muito mais intensificado das TIC.

Neste contexto, "educação a distância" deixa de ser apenas mais uma modalidade de educação para se tornar sinônimo de uma nova fatia de mercado, muito rentável, para a indústria da comunicação e o setor privado da educação. Considerar o ensino a distância como solução para carências educacionais e/ou rejeitá-lo por qualidade insuficiente é colocar mal a questão, porque disfarça as questões mais importantes para a compreensão do fenômeno: seu caráter econômico, que determina muitas práticas, e suas características técnicas, que apontam para aquela "convergência de paradigmas", isto é, para a mediatização técnica dos processos educacionais, como, aliás é sempre bom lembrar, já ocorreu com os processos de comunicação.

\section{Educação a distância no Brasil}

Embora não seja o único fator determinante, a tecnologia está fortemente associada ao desenvolvimento da educação a distância: dos trens americanos avançando para o oeste selvagem, levando a civilização, ao ciberespaço invadindo nossas casas e cativando nossa atenção e nossas crianças, o avanço técnico nos meios de comunicação sempre impulsionou o desenvolvimento de experiências de ensino a distância (Carmo, 1998).

No Brasil (país historicamente dado a grandes experimentos tecnológicos inovadores na educação, que acabam por se tornar "elefantes brancos", pela incúria do poder público e visão tacanha do setor privado), tem havido experiências de educação a distância nas 
quais se pode observar algumas características estruturais recorrentes: as políticas públicas do setor têm um caráter tecnocrático, autoritário e centralizador que as destina necessariamente a resultados medíocres, senão ao fracasso, ao passo que a iniciativa privada vai ganhando terreno, construindo competência e obtendo verbas públicas. No Brasil, é difícil pesquisar sobre os aspectos propriamente técnicos ou pedagógicos das experiências de uso educativo de tecnologias como a televisão, o computador, a telemática, ou mesmo o rádio, porque esbarramos sempre nas determinações econômicas e políticas. As propostas são tecnocráticas no sentido em que, às vezes válidas do ponto de vista puramente técnico, não levam em consideração as condições (sociais e políticas, micropolíticas) de realização, o "chão social” de que fala Santos em sua tese sobre o projeto Saci, exemplo emblemático da consciência tecnocrática:

Portanto a razão do fracasso de muitos projetos de educação para o desenvolvimento deve ser buscada lá mesmo onde se encontram bloqueadas as veleidades da escola nos países subdesenvolvidos, isto é, no conjunto dos fatores sócio-econômicos e culturais, no chão social sobre o qual os projetos são construídos. Ora, o que importa aqui é que, freqüentemente, o chão social compromete não só as experiências, mas com elas, a intenção de avaliá-las. (Santos, 1981, p. 169, meu grifo)

A última afirmação do autor é extremamente importante e merece ser destacada. As condições concretas de implementação das políticas propostas, aí incluídos os interesses políticos em jogo, não apenas prejudicam sua efetividade como obnubilam a compreensão do processo de inovação tecnológica na educação, mascaram as avaliações, escondendo fracassos e canalizando os eventuais sucessos da ação educacional como dividendos para interesses políticos eleitorais. O caso do projeto Viva Educação do governo do Maranhão, referido a seguir, que propõe a expansão do ensino médio por meio da educação a distância, parece ser um exemplo bem atual do uso político do discurso tecnocrático: exatamente como fez seu pai há mais de 30 anos (Belloni, 1984), a governadora escolhe não recrutar e formar professores e propõe a expansão do ensino médio via televisão, sem professores especializados. A associação com a Fundação Roberto Marinho, com repasse de gordas verbas públicas, destinadas à educação, para que a empresa aplique seu já ultrapassado curso supletivo, Telecurso 2000, remete a nebulosos negócios de marketing político da família Sarney em campanha pela presidência da república (ver hipertexto 2 ). 
A questão é complexa e envolve aspectos políticos e econômicos que muitas vezes dificultam a compreensão dos aspectos conceituais, propriamente educacionais e técnicos. Buscando maior clareza na análise do fenômeno, podemos tentar uma classificação provisória, num panorama rápido da história da educação brasileira da segunda metade do século 20, das principais experiências de educação a distância em quatro grandes tipos, segundo dois critérios essenciais: objetivos pedagógicos e públicos prioritários.

\subsection{Formação de professores}

Neste tipo se incluem programas de grande porte dos governos federal ou estaduais destinados à formação de professores, dentre os quais se destacam as iniciativas mais recentes do MEC, com os programas de formação continuada Um Salto para o Futuro (1991) e TV Escola (1996) e a primeira experiência de formação inicial de professores do ensino básico feita a distância no Brasil, a licenciatura de pedagogia desenvolvida no estado de Mato Grosso (Licenciatura Plena em Educaşão Básica: $1^{\circ} \stackrel{a}{a}$ $4^{\underline{o}}$ série do $1^{\underline{a}}$ grau).

Essa experiência, realizada pela Universidade Federal do Mato Grosso, em parceria com os governos do estado e dos municípios, merece destaque por seu caráter duplamente inovador: inova na proposta curricular, totalmente voltada para as séries iniciais do ensino fundamental e não para a formação do especialista em pedagogia; e na metodologia, baseada em técnicas de educação a distância, combinadas com atividades presenciais e um sistema descentralizado de acompanhamento do estudante. Graças a estas estratégias - que combinam técnicas de ensino a distância, uso diversificado de tecnologias de informação e comunicação (materiais impressos e audiovisuais; tutoria via fax, telefone e rede telemática) e sistema de acompanhamento (tutoria) individual e coletivo, presencial e a distância - a experiência do Mato Grosso conseguiu titular sua primeira turma de 300 alunas, em quatro anos (1999), com índices de evasão muito baixos. Para tal sucesso concorreram também, muito provavelmente, políticas de valorização e formação de professores por parte das autoridades estaduais e municipais, que asseguraram condições satisfatórias de auto-estudo individual e coletivo nas escolas (local de trabalho), viabilizando a participação efetiva das professoras no curso, estimulando a motivação sem a qual não há aprendizagem (Alonso, 1999).

Motivação e políticas mais efetivas de valorização do magistério parecem ser justamente o que falta para uma maior participação dos 
professores na experiência de implantação da TV Escola no estado de Santa Catarina, objeto de nossa pesquisa, realizada em 1999/2000, e que revelou os mesmos problemas já encontrados em pesquisa anterior sobre a experiência semelhante da implantação do Programa Um Salto para o Futuro, em 1996 (hipertexto 1).

Hipertexto 1: Formação continuada de Professores via televisão.

A TV Escola é um programa de grande porte do Ministério da Educação (Secretaria de Educação a Distância - SEED) cujo objetivo é oferecer, aos professores da educação básica, oportunidades de formação continuada, na modalidade a distância, buscando contribuir de forma aberta, flexível e informal (não-regular, sem avaliação nem certificação) para a melhoria daquela formação.

Embora seja apresentada como novidade pela SEED/MEC, a TV Escola se baseia e amplia a proposta e a estrutura básica do Programa Um Salto para o Futuro, criado pela TVE do Rio no início da década de 90 . Os objetivos do Programa Um Salto para o Futuro, como os da TV Escola, referem-se à formação continuada (isto é, de cunho permanente e em serviço) de professores do ensino fundamental. O programa foi iniciado em 1992 e era baseado na difusão televisual diária e ao vivo com uma comunicadora e dois especialistas que apresentavam o assunto do dia e respondiam às questões dos telespectadores. Do ponto de vista das técnicas de comunicação e das estratégias de recepção, os dois programas diferem bastante: enquanto o primeiro ia ao ar ao vivo, com recepção organizada e com possibilidades de participação direta de alguns cursistas via telefone ou fax, a TV Escola transmite três vezes ao dia o mesmo bloco de programação, e baseia sua estratégia na gravação e organização para posterior uso dos programas pelos professores.

O Programa TV Escola, criado em 1996 pela Secretaria de Educação a Distância/MEC, pretende disseminar de forma mais rápida, ampla e democrática uma programação que desenvolva e estimule a interação e o intercâmbio de informações entre professores. Com isso visa a formar, aperfeiçoar e valorizar os professores para melhorar o ensino e reduzir as taxas de evasão e repetência nas escolas.

O programa destina-se a professores, diretores, funcionários e alunos das escolas públicas de educação básica. Beneficia escolas com mais de 100 alunos, num total de 900 mil professores e 23 milhões de alunos - cerca de 85\% dos estudantes do ensino fundamental. Tal programa espera atingir também a comunidade associada à escola, sendo uma nova fonte de acesso à cultura e ao conhecimento, por intermédio do programa Escola Aberta, que é transmitido aos sábados e conta com programas voltados para o lazer.

Originalmente criada para atender prioritariamente aos professores das séries iniciais do ensino fundamental, cuja formação de nível médio exige uma decisiva complementação, a TV Escola foi ampliando sua abrangência e hoje se dirige para professores de todos os níveis da educação básica. Ao mesmo 
tempo em que foi ampliando sua clientela-alvo, a TV Escola foi também mudando de enfoque quanto à natureza de seus objetivos prioritários, passando a oferecer cada vez mais materiais didáticos para os professores utilizarem com seus alunos em sala de aula. Nossa pesquisa mostrou que os professores que mais utilizam os programas da TV Escola são os professores especialistas das diferentes disciplinas das séries finais do ensino fundamental e médio, e que a grande maioria os utiliza como materiais didáticos em suas disciplinas específicas, em sala de aula com os estudantes. O uso desses programas para sua própria formação é muito minoritário entre os professores.

Essa mudança de enfoque, de público prioritário e de tipo de utilização revela mais uma vez um epifenômeno (efeito não desejado?) recorrente em muitas experiências de formação de professores no Brasil: os profissionais que acabam se beneficiando mais destes programas são justamente aqueles que deles necessitam menos (os que já têm uma melhor formação) e não aqueles que precisam mais e que são o público prioritário das ações de formação. Este fenômeno ocorre de modo freqüente e explica muito da pequena eficácia de programas de formação continuada de professores e o baixo efeito multiplicador desses programas: os professores com melhor formação estão mais aptos a aproveitarem melhor as oportunidades abertas de formação, ao passo que aqueles que mais necessitam reforços em sua formação não têm as condições mínimas para aproveitá-las (não têm hábitos de auto-estudo, têm jornadas de trabalho duplas ou triplas, são mal remunerados e moram longe).

Em que pesem suas boas intenções e a qualidade quase sempre bastante boa da programação oferecida, o sucesso da TV Escola esbarra nos problemas estruturais dos sistemas de ensino público no Brasil, que não estão preparados para assegurar sua parte na estratégia proposta: os equipamentos em geral não funcionam satisfatoriamente (por problemas relacionados aos mecanismos oficiais descentralizados de compra e manutenção), e não há pessoal minimamente disponível e preparado para gravar os programas e organizar as videotecas escolares. Além destes problemas operacionais, extremamente importantes pois impedem a utilização efetiva da TV Escola, é preciso ressaltar duas questões principais que explicam os baixos índices de uso dos programas para a formação continuada de professores: a ausência de tempo para formação, previsto dentro da jornada de trabalho, e a inexistência de ações de formação coletiva integradas aos projetos pedagógicos das próprias escolas, e patrocinadas e incentivadas pelas autoridades locais e regionais de educação. $\mathrm{Na}$ falta deste tipo de ação, a formação continuada dos professores passa a ser uma responsabilidade individual, exatamente nos moldes do modelo pós-fordista: as oportunidades estão dadas, os programas chegam até as escolas, o estado cumpriu sua função, os professores é que não sabem (ou não querem aproveitar). A característica recorrente das políticas de ensino a distância no Brasil, a ênfase quase exclusiva nos sistemas ensinantes, toma aqui uma dimensão extrema, com a preocupação única de produção de materiais, para distribuição totalmente aberta, como é próprio do mercado. 


\subsection{Educação popular}

Correspondem a este tipo experiências de televisão educativa muito variadas visando à educação popular, não-formal, tanto no sentido lato, de informação e divulgação do conhecimento e (teoricamente) de formação da cidadania, quanto no sentido estrito de educação supletiva. Dentre estas últimas, as mais conhecidas (além dos pioneiros MEB Movimento de Educação de Base - e Projeto Minerva) são os cursos de alfabetização de adultos do Mobral e os "telecursos" produzidos pela Rede Globo em parceria com órgãos públicos e para-oficiais:Telecurso de $2^{\underline{a}}$ grau, 1979, Fundação Padre Anchieta/TV Cultura de São Paulo; Telecurso de $1^{\underline{a}}$ grau, 1984, Funteve/TV Educativa do Rio; Telecurso 2000, 1995, Sesi/SP. Em geral trata-se de iniciativas oficiais em parceria com instituições privadas.

A matriz comunicacional das propostas pedagógicas desses programas, como de muitos outros no Brasil ainda hoje, é a telenovela, e o programa que transpôs a proposta estética e a estrutura narrativa da telenovela brasileira para o discurso didático foi a novela João da Silva, experiência pioneira e inovadora de ensino supletivo a distância, produzida nos anos 60 por uma equipe da TVE do RJ, composta de pedagogos, professores e comunicadores. Faz parte também desta categoria, sendo talvez seu melhor exemplar e, sem dúvida, seu maior sucesso de público, a série infantil $O$ Sítio do Pica-Pau Amarelo, cuja concepção foi fruto de pesquisas de equipes da TV Educativa do Rio de Janeiro. Esta emissora pública (criada em 1969 e vinculada ao MEC) assegurou também o primeiro ano de produção, em parceria com a TV Globo que "cedia" seus astros, levando, em contrapartida, todos os direitos sobre o produto, que ela reproduziu com grande sucesso comercial durante vários anos (Belloni, 1984, hipertexto 2).

Hipertexto 2: A TV Globo na educação a distância.

Outro exemplo do tipo educação popular lato sensu foi o remake brasileiro da série americana Sesame Street, que a TV Globo produziu em parceria com a TV Cultura de São Paulo. Esta foi a primeira grande experiência educativa no Brasil e da TV Globo: o programa foi totalmente reproduzido no Brasil, utilizando somente os roteiros do original americano. Para esta realização, foram especialmente equipados os estúdios da TV Cultura de São Paulo, que forneceu também a maior parte dos equipamentos e a coordenação pedagógica; A TV Globo entrou com os atores e pessoal técnico. Essa série, produzida em 1970, foi a primeira grande experiência brasileira de uso efetivamente pedagógico do meio televisual de massa e foi um grande sucesso tanto em termos de público e de 
continuidade (132 programas de 55 minutos) como em qualidade pedagógica. Este sucesso contribuiu significativamente para o aumento das audiências em todas as emissoras da rede Globo de televisão. Mecanismos eficientes de marketing foram acionados e os lucros daí resultantes em muito contribuíram para a expansão econômica das Organizações Globo, que já nessa época era o mais importante sistema de comunicação no Brasil. A TV Cultura transmitiu Vila Sésamo durante algum tempo, atingindo um público reduzido, na cidade de São Paulo.

Esta primeira experiência já apresenta o traço essencial que marcará a atuação da Rede Globo no setor educacional, a associação com um órgão público que lhe oferece três vantagens significativas: (i) custeia grande parte da produção; (ii) confere qualidade pedagógica ao produto; (iii) e credibilidade à emissora que se autopromove como benfeitora da educação do povo. Tudo isto favorecendo a exploração comercial do programa com grandes benefícios para a empresa.

Em 1976, a TV Globo decide realizar outra programação infantil educativa para substituir Vila Sésamo, "saturado" após tantos anos de difusão. Foi escolhido um tema bem brasileiro: a inesgotável obra de Monteiro Lobato, cujas histórias tinham povoado a infância dos brasileiros desde os anos 30, cujos direitos a TV Globo já havia comprado. Para a produção de O Sítio do Pica-Pau Amarelo, a TV Globo busca de novo um parceiro no setor público: a TV Educativa do Rio de Janeiro, com o apoio direto do Departamento de Ensino Fundamental (DEF) do MEC. Os respectivos papéis destas instituições foram explicitados no acordo assinado, cabendo à Globo as decisões e a responsabilidade relativas à produção; à TV Educativa, a tarefa de prestar assistência técnica e pedagógica e de fornecer os estúdios e equipamentos (ou seja, toda a infraestrutura de produção); e ao DEF/MEC a função de legitimar o projeto, incluindo o programa na estrutura da educação infantil.

O acordo era perfeito para os interesses da instituição privada: a televisão pública fornecia instalações e equipamentos, e ainda assegurava o trabalho pedagógico, sem no entanto ter a coordenação pedagógica, reservada à Globo. Tal acordo tornava impossível qualquer outra realização da emissora pública, cuja capacidade de produção era bastante limitada. A TV Globo assegurava assim duas vantagens: de um lado, economizava custos de produção, e de outro, eliminava a concorrência da emissora pública, reduzida a parceiro menor nessa produção. O Sítio do Pica-Pau Amarelo foi inicialmente concebido como material pedagógico de preparação do público infantil à entrada na escola, especialmente à alfabetização. Esta proposta pedagógica todavia será abandonada quando a produção da série passa totalmente para a Globo que, uma vez o programa testado e com sucesso garantido, monta um estúdio especialmente preparado para sua produção, e o explora durante vários anos acumulando lucros significativos. As vantagens comerciais derivadas deste tipo de produção são enormes e as necessidades de ampliação da faixa etária do público-alvo (de pré-escolar a infanto-juvenil, segundo as regras técnicas da comunicação) fizeram praticamente desaparecer do programa os conteúdos didáticos e a abordagem pedagógica, o que o transformou em mais uma telenovela global. 
Em 1977, as Organizações Globo criam uma nova instituição, a Fundação Roberto Marinho, com o objetivo de "promover e difundir atividades ligadas à educação, de caráter científico, cultural, educativo e esportivo". Essa fundação evidentemente não tem fins lucrativos, o que a habilita para receber outros recursos públicos, além dos impostos que as empresas do grupo Globo deixam de recolher para aplicar na FRM. A partir de então, a FRM vai assegurar a entrada em grande estilo da Globo no mercado da educação a distância propriamente dito, associando-se em 1978 com a TV Cultura de São Paulo (Telecurso de $2^{\underline{a}}$ grau) e com a Universidade de Brasília, em 1980, para a produção de um outro telecurso para o ensino supletivo, dessa vez de $1^{\underline{a}}$ grau (Belloni, 1984).

\subsection{Televisão escolar substitutiva}

Exemplos deste tipo são as experiências de televisão escolar, de caráter compensatório, visando a sanar carências no ensino básico regular e viabilizar rapidamente a expansão da oferta de ensino básico, demandas decorrentes de reformas educacionais (por exemplo, o ensino de $1^{\underline{a}}$ grau, criado pela reforma de 1971, especialmente para as séries finais, carentes de professores qualificados e, nos anos 90, o ensino médio, idem). A estratégia desse tipo de experiências, ocorridas em vários países do Terceiro Mundo nos anos 70, baseia-se no uso intensivo de um meio tecnológico (no caso, a televisão), que possibilitaria substituir rápida e efetivamente, não a função pedagógica do professor (muitas vezes entendida como simplesmente disciplinar), mas sua formação especializada.

No Brasil, três estados do Nordeste desenvolvem até hoje experiências de televisão escolares (Ceará, Rio Grande do Norte e Maranhão), herança dos planos mirabolantes da então chamada "tecnoestrutura" no poder durante o regime militar. A experiência mais desastrosa desse tipo foi o famoso Projeto Saci, que propunha difundir ao mesmo tempo para todas as escolas brasileiras, por televisão via satélite, as mesmas aulas, com qualidade "didática" garantida pela produção centralizada de programas e dispensando assim a formação especializada dos professores locais , transformados em "monitores polivalentes". A produção era localizada no Inpe, Instituto de Pesquisas Espaciais, em São Paulo, instituição responsável pelo projeto, desde sua concepção inicial por engenheiros e militares americanos e brasileiros. A própria localização institucional revela claramente o caráter tecnocrático e a perspectiva estritamente técnica do Projeto Saci, cuja prioridade era experimentar as potencialidades do satélite de comunicação, sendo a educação mero pretexto.

Tal proposta absurda, típica do discurso tecnocrático que ainda assola o país, correspondia, evidentemente, aos interesses da indústria 
americana que na época precisava testar e vender sua novíssima tecnologia de telecomunicação, o satélite (Santos, 1981; Belloni, 1984). Esta mesma reflexão pode ser feita hoje, sobre a videoconferência que, não tendo encontrado a aceitação prevista pelos fabricantes entre as empresas, foi transposta para a educação a distância, e aí apresentada como a grande solução para o problema da comunicação unívoca e diferida dos meios anteriores (TV, impresso). Não tendo alcançado os resultados esperados, este recurso técnico high tech, após poucos anos de uso, já está sendo considerado pesado e obsoleto, embora continue a ser usado especialmente em experiências do tipo quatro, que veremos a seguir.

O exemplo mais recente deste tipo de experiência de televisão escolar substitutiva é a proposta do governo do Maranhão de substituir o ensino médio regular por um ensino supletivo a distância, sob pretexto de queimar etapas, atingir rapidamente os milhares de jovens da faixa etária que estão fora da escola e alcançar índices mais aceitáveis pelos organismos internacionais de fomento, e pela opinião pública nacional importante para as pretensões eleitorais da governadora (hipertexto 3).

Hipertexto 3: Projeto Viva Educação: ensino médio para todos via TV.

Em novembro de 2000 o governo do Estado do Maranhão e a Fundação Roberto Marinho firmaram um convênio milionário (os números variam entre 102 e 114 milhões de reais por ano!!) para a implantação do Projeto Viva Educação, que pretende atingir, em dois anos, mais de 150.000 mil alunos, oferecendo ensino de nível médio na modalidade a distância, com materiais do Telecurso 2000 da FRM e montagem de mais de 3.000 telessalas. As justificativas para tal investimento referem-se à necessidade de expansão rápida e com qualidade do ensino médio no estado, visando a incluir aqueles milhares de jovens que não tiveram acesso ou que estão atrasados em sua escolaridade.

A governadora admite, após seis longos anos no poder (e quantos mais de influência de sua família), que o governo do estado mantém escolas de ensino médio em apenas 60 dos 217 municípios do estado! O Projeto Viva Educação viria agora, via televisão, melhorar os índices de oferta de educação públi$\mathrm{ca}$, e possibilitar a melhoria da qualidade do ensino ofertado. De fato, a proposta significa substituir a oferta de ensino regular em nível médio por um ensino supletivo utilizando materiais do Telecurso 2000 e, o que é o pior problema desta proposta, substituindo os professores especializados, formados pelas universidades, por monitores formados pelo próprio projeto.

Embora a cargo da FRM, o projeto poderá ser "terceirizado", já que a FRM pretende entregar a gestão e execução do programa no Maranhão a uma outra Fundação, a Fundação Getúlio Vargas, ambas instituições com ótimo currículo em outras áreas, mas nenhuma experiência com ensino médio ou com o Estado 
do Maranhão. O que explica a escolha de tais instituições, alheias ao estado, ao invés de mobilizar instituições locais, como, por exemplo, as universidades ou a própria TV Educativa do Maranhão, herança do governo Sarney pai?

Os educadores maranhenses protestam apontando para as evidentes falhas da proposta, não só no que se refere à qualidade do ensino oferecido, que pretende substituir o ensino médio regular de três anos por um curso supletivo de 15 meses, mas também no que isto significa em termos de política de pessoal no setor educacional: o governo deixou de realizar um concurso público previsto para recrutar professores para o ensino fundamental e médio para investir neste projeto mirabolante de ensino a distância.

O governo busca legitimar tal escolha por meio de um discurso modernizante e tecnocrático que afirma a primazia da técnica, erigida em estratégia salvadora. Na prática, porém, a política de educação da governadora Sarney está atrelada e é resultado do jogo de interesses políticos vinculados à sucessão presidencial de 2001: ao mesmo tempo que garante a amizade e a boa vontade midiática da Rede Globo, Roseana Sarney precariza as condições de trabalho dos educadores maranhenses, fragilizando uma possível fonte de oposição, inclusive nas universidades formadoras de professores, que estão completamente à margem deste processo.

O que é mais interessante ressaltar neste episódio é a incrível semelhança com a criação, há mais de 30 anos, nesse mesmo pobre estado, da TV Educativa do Maranhão, concebida e implantada pelo então governador José Sarney. Também naqueles tempos de hegemonia do discurso que o campo da educação convencionou mais tarde chamar "tecnicista", as justificativas e os objetivos referiam-se à possibilidade de resolver rapidamente problemas educacionais, carências e déficits acumulados por anos de incúria e desleixo do poder com a educação pública, com o uso intensivo de tecnologias importadas, caras e estrangeiras aos costumes da população. População esta que, aliás, nunca é chamada a dar sua opinião, a não ser nas grandes datas eleitorais, quando é embalada pelo canto de sereia do marketing político.

O que este acordo do governo do Maranhão com a Fundação Roberto Marinho indica é a recorrência de uma característica estrutural da política educacional no Brasil: o poder público parece investir na permanência e no agravamento das carências - deixando os sistemas públicos de ensino morrerem à míngua para, a cada evento eleitoral, poder surgir com soluções milagrosas e de curto prazo, que permitem canalizar recursos públicos para campanhas políticas privadas e podem criar a impressão momentânea de que o governo está interessado em resolver os problemas da população (Jornal Pequeno, 22/11/2000).

\subsection{Formação continuada ou educação ao longo da vida}

Classificamos nesta categoria experiências muito variadas de formação continuada, principalmente em nível de pós-graduação, desenvolvidas por empresas privadas das áreas de educação e/ou 
comunicação, mas também por universidades públicas. Abrangem uma variedade muito grande de cursos de formação pós-graduada, de atualização profissional, reconversão e outros tipos, dirigindo-se a um mercado consumidor muito amplo. Esse tipo de oferta, cuja lógica é a de mercado, não difere muito, na essência, de antigas experiências de ensino por correspondência, do tipo do Instituto Universal Brasileiro, e tende a gerar produtos de qualidade duvidosa.

Cabe contextualizar esse tipo de experiência, que é representativa de um novo "nicho" de mercado muito promissor no capitalismo globalizado deste início de século. As mudanças sociais ocorridas nas últimas décadas - no modo de produção econômica, na organização e gestão do trabalho, no acesso ao mercado de trabalho e nos processos culturais cada vez mais mundializados e mediatizados pelas técnicas estão a exigir transformações radicais nos sistemas educacionais que, para adaptar-se às novas demandas, vão assumindo novas funções e enfrentando desafios.

Neste quadro de mudanças do capitalismo tardio, a educação a distância aparece como um novo filão do mercado educacional, que tende a ser extremamente promissor do ponto de vista econômico, principalmente com as possibilidades de multiplicação derivadas do uso intenso das tecnologias de informação e comunicação (Belloni, 1999 e 2001a). Em breve teremos oferta de cursos de praticamente todas as grandes universidades do mundo (especialmente as americanas), que estarão disponíveis no mercado mundial, por intermédio dos mais diversos meios. Os exemplos mais conhecidos desse tipo são os inúmeros cursos de atualização oferecidos por empresas, associações profissionais ou universidades, aproveitados de modo flexível e individual por diferentes categorias profissionais (médicos, engenheiros etc.). Outro tipo de exemplo se refere a cursos de pós-graduação stricto sensu oferecidos por instituições de ensino superior e que tendem a reproduzir de modo "aligeirado" o ensino convencional (hipertexto 4).

Novos formatos para esse tipo de educação a distância vão aparecendo, relacionados com as novas tecnologias de informação e comunicação, cujas potencialidades comunicacionais apontam para novos tipos de aprendizagem mais abertas e mais flexíveis. Aprendizagem aberta e flexível é justamente a proposta dos "portais” direcionados à educação. Os limites entre educação, informação e entretenimento tendem a perder nitidez nas sociedades contemporâneas, onde o indivíduo consome quantidades crescentes de informação, aplicando-as tanto ao trabalho quanto à vida afetiva e ao lazer. 
Hipertexto 4: Educação ao longo da vida como novo nicho de mercado.

Um exemplo deste tipo, desenvolvido por uma universidade pública, é o Laboratório de Educação a Distância - LED/UFSC, que oferece cursos em convênio com diferentes tipos de empresa, especialmente com faculdades particulares de vários pontos do país. Criado em 1995, pelo Departamento de Engenharia de Produção da Universidade Federal de Santa Catarina, o LED objetivava atender às demandas empresariais, setor com o qual o Departamento já mantinha contatos e parcerias. Para as empresas, a vantagem da educação a distância é evidente: poder qualificar seu pessoal sem ter que abrir mão de seu tempo de trabalho. A infra-estrutura técnica, baseada principalmente na videoconferência, foi montada graças a financiamentos públicos, especialmente do governo do estado.

Com base em suas primeiras experiências, o LED foi se ampliando, oferecendo novos cursos, incorporando novas técnicas, buscando novos mercados. Tendo realizado, no início de suas atividades, uma experiência local de formação de professores em convênio com a Secretaria estadual de Educação, o LED, partir de 1998, passou a atender um novo segmento de mercado, em grande expansão: os professores do ensino superior, básico e/ou técnico, necessitados não só de titulação compatível com as exigências legais (LDB/1996) como de uma formação científica e pedagógica adequada. Para atender a esta demanda, o Programa de Pós-Graduação em Engenharia de Produção (PPGEP) criou uma área de concentração específica: Mídia e Conhecimento, que oferece uma formação em tecnologias da educação, a distância, em parceria com instituições públicas e privadas de ensino superior e técnico.

Uma avaliação impressionista de um desses cursos de formação de professores, para o ensino superior, em nível de mestrado (resultado de uma "observação participante" como professora orientadora), permite dizer que esse tipo de formação de professores tende a atuar de modo bastante perverso, podendo agravar os problemas de qualidade do ensino superior privado, já bastante comprometida. Isso porque tende a criar uma espécie de "rede de mediocridade" porque professores de todas as áreas do conhecimento obtêm sua titulação numa mesma área de concentração - Mídia e Conhecimento - que nada tem a ver com o conteúdo de seu ensino ou com o avanço científico em sua disciplina. Trata-se da reprodução da baixa qualidade a preços ao consumidor nem tão baixos: esses professores são em sua maioria egressos de pequenas instituições privadas de ensino superior, e nunca tiveram acesso ao ambiente acadêmico e ao ensino de melhor qualidade das grandes universidades, e encaram esses cursos como representativos daquele ambiente, pagando caro por eles.

Os meios técnicos utilizados são as diferentes aplicações da rede telemática, principalmente a videoconferência, como modo de ensino, e o correio eletrônico, como forma de contato ou interação do estudante com a instituição. A videoconferência, técnica considerada de ponta poucos anos atrás, posta no mercado visando às empresas (parecia perfeita para reuniões a distância de executivos muito ocupados), acabou não fazendo o sucesso esperado e sendo desviada para um novo nicho de mercado das TIC, a educação a distância. 
Apresenta certas vantagens no sentido da interação síncrona com os estudantes e da utilização de documentos gráficos. Do ponto de vista pedagógico, no entanto, a videoconferência tende a reforçar os velhos métodos da aula expositiva, centrados na figura do magister, acrescentando-lhes uma rigidez técnica que exige muito dos professores e não melhora a motivação dos alunos.

\section{Conclusões provisórias}

Embora parcial e imperfeita, a rápida "tomada panorâmica" apresentada acima permite ter uma idéia das questões mais gerais do ensino a distância no Brasil, embora de um modo um tanto impreciso, como num retrato impressionista, no qual se percebem os contornos mas não os detalhes dos objetos. Com efeito, encontramos as mesmas contradições, que caracterizam a história da educação no Brasil: de um lado, a contradição entre a teoria das custosas propostas tecnocráticas concebidas nos gabinetes e a prática da falta de condições reais de sua efetivação; e de outro, o (aparente) conflito entre o setor público com suas políticas equivocadas que criam um mercado florescente, livre de restrições para o lucro do setor privado. Estas características, evidentemente, não são típicas somente do Brasil, mas inserem-se num contexto maior do capitalismo mundialem que ocupamos um lugar preciso de mercado consumidor e no qual as políticas públicas dos países periféricos obedecem às regras e seguem os modelos das agências financiadoras internacionais.

Também de um ponto de vista técnico, podemos observar algumas recorrências encontradas tanto em relatos de pesquisas (inclusive as nossas) como em reportagens jornalísticas: os problemas destas experiências de $\mathrm{EaD}$ não se situam tanto no lado da oferta, ou seja, do ensino, no qual a qualidade varia muito, mas de modo geral não é totalmente ruim, sendo possível aproveitá-las com resultados satisfatórios. Os problemas estão no lado da demanda, ou seja, da aprendizagem, na qual não há tradição nem condições de auto-estudo, em que a recepção (seja TV, seja internet, seja impresso) dos materiais é tecnicamente ruim e a motivação para a aprendizagem é muitas vezes inexistente (onde uma professora do ensino fundamental, que teve uma péssima formação inicial, ganha um salário mínimo e trabalha em condições miseráveis, irá buscar motivação para estudar a distância em suas horas livres?).

Pesquisas empíricas com professores usuários da TV Escola, por exemplo, têm mostrado a recorrência de dois tipos de problemas dificultadores do uso da TV Escola pelos professores, seja para sua 
formação, seja como material didático: os problemas técnicos ligados à qualidade e manutenção dos equipamentos; e o problema do tempo, tanto em sua dimensão física, ligada à jornada de trabalho, quanto em sua dimensão simbólica, relacionada com os materiais e as novas possibilidades de comunicação simultânea ou diferida (Neto, 2001; Belloni, 2001c).

A questão do tempo tem sido o nó górdio dos programas de $\mathrm{EaD}$, juntamente com o material didático utilizado. Não tem sido diferente com a TV Escola. Enquanto a dimensão do espaço pode ser resolvida com materiais interativos e/ ou uso de tecnologias como o telefone, o fax e o e-mail que facilitam a comunicação entre o professor e o aprendente, a questão do tempo é mais complexa, uma vez que possui, em seu interior, dimensões e aspectos que interferem no processo educativo. (Toschi, 2000)

Os problemas relacionados com o tempo são fundamentais em $\mathrm{EaD}$, não apenas em suas dimensões física, institucional e imaginária, que formam a base das relações temporais concebidas por cada indivíduo e estabelecidas na sociedade, mas também em sua dimensão econômica, de medida do tempo de trabalho, definidora das condições de trabalho e de formação dos trabalhadores. A ausência de um tempo para a formação continuada, previsto especificamente para este fim, dentro da jornada de trabalho dos professores, é provavelmente a causa principal da baixa efetividade do Programa.

Do ponto de vista sociológico, e a partir do exposto acima, a questão pode ser assim resumida: políticas públicas tecnocráticas geram propostas educacionais centradas nos processos de ensino (estrutura organizacional, planejamento, concepção, produção e distribuição de materiais etc.), que correspondem mais a interesses políticos e econômicos do que a demandas e necessidades, e não nos processos de aprendizagem (características e necessidades dos estudantes, modos e condições de estudo, níveis de motivação etc.), o que, em educação a distância, é fatal. Ou seja, os modelos de educação a distância vigentes no país, especialmente os de formação de professores e particularmente a TV Escola, referem-se muito mais aos "sistemas ensinantes" do que aos "sistemas aprendentes" (Carmo, 1998; Belloni, 1999).

Do ponto de vista pedagógico, podemos dizer que, mesmo quando são fundamentadas em teorias psicopedagógicas inovadoras (construtivismo, sociointeracionismo, interculturalismo), como por exemplo a proposta pedagógica da TV Escola, a maioria das experiências não consegue romper tendências enraizadas na instituição escolar - incluindo 
aí a formação inicial e continuada de professores - de compartimentar o saber nas grandes áreas do conhecimento, de enfatizar os conteúdos em detrimento da capacidade de aprender e de resistir à integração de novas tecnologias. Tendências que ainda permanecem na formação inicial de professores em nossas melhores universidades, apesar das mudanças ocorridas recentemente com a definição de novos parâmetros curriculares para a educação nacional.

As intenções inovadoras e de interdisciplinaridade, presentes nos materiais da TV Escola e do Programa Um Salto para o Futuro não atingem seus objetivos, e os resultados no lado da utilização - as formas como os usuários se apropriam deste conhecimento - não mostram esta integração pedagógica entre as disciplinas, e menos ainda uma prática mais ativa e centrada no aluno. Ao contrário, nem professores, nem escolas costumam abrir espaços em suas agendas carregadas de conteúdos para desenvolver atividades "extracurriculares" de discussão de temas extremamente importantes para os jovens (e, portanto, com alto potencial de motivação) tais como sexualidade, violência, mídias, meio-ambiente, profissões. Torna-se mais uma vez evidente que os programas de formação continuada e mesmo as propostas curriculares mais inovadoras não têm conseguido romper a barreira entre a teoria inovadora e a prática convencional nem entre políticas tecnocráticas e "propagandeiras” e as condições precárias de realização efetiva dessas políticas.

É preciso lembrar que as determinações político-administrativas interferem na concepção e implementação de ações educacionais de grande porte como a TV Escola e antes dela o Programa Um Salto para o Futuro, fragilizando suas propostas e resultados. Um exemplo disso pode ser visto no fato de a Fundação Roquette Pinto, que desde sua criação, em 1969, pertenceu ao Ministério da Educação, ter sido transferida, em 1996, para a Secretaria de Comunicação da Presidência da República, cuja atribuição é a propaganda do governo federal, incluindo a gestão das gordas verbas publicitárias. Esta medida se integra à política do Ministério da Educação de modo assaz contraditório: ao mesmo tempo em que cria a Secretaria de Educação a Distância e a TV Escola, que produz e distribui programas televisuais, o MEC se desfaz da infra-estrutura técnica de produção e distribuição desse tipo de programa. Evidentemente esta política é coerente com o ideário liberal de terceirização de serviços técnicos, mas esta explicação não é suficiente, outras podem ser buscadas nas políticas de comunicação do governo federal.

Chegamos então a uma conclusão provisória e um tanto óbvia que talvez pudesse ajudar a compreender melhor o fenômeno em estudo: a 
questão fundamental não está tanto na modalidade do ensino oferecido se em presença ou a distância, a convergência dos dois paradigmas sendo a tendência mais evidente - mas sobretudo na capacidade de os sistemas ensinantes inovarem quanto aos conteúdos e às metodologias de ensino, de inventarem novas soluções para os problemas antigos e também para aqueles problemas novíssimos gerados pelo avanço técnico nos processos de informação e comunicação, especialmente aqueles relacionados com as novas formas de aprender (Perriault, 1996; Carmo, 1998).

A educação está se transformando tanto em termos de finalidades sociais quanto no que diz respeito a estratégias e modalidades, notadamente com a introdução de meios técnicos e com a tendência a uma maior flexibilidade de acesso, currículos e metodologias. A educação a distância surge neste quadro de mudanças como mais um modo regular de oferta de ensino, perdendo seu caráter supletivo, paliativo ou emergencial, e assumindo funções de crescente importância, principalmente no ensino pós-secundário, seja na formação inicial (ensino superior regular), seja na formação continuada, cuja demanda tende a crescer de modo exponencial, em virtude da obsolescência acelerada da tecnologia e do conhecimento. Nas sociedades contemporâneas, "do conhecimento" ou "da informação", a formação inicial torna-se rapidamente insuficiente e as tendências mais fortes apontam para uma "educação ao longo da vida" (lifelong education) mais integrada aos locais de trabalho e às necessidades e expectativas dos indivíduos. São estes dois grandes desafios que os sistemas de ensino superior enfrentam agora e para os quais a educação a distância pode contribuir: expansão significativa e diversificação da oferta de formação inicial, para atender à demanda decorrente da expansão do ensino secundário; criação de novos modos de formação continuada adequada às demandas do mercado de trabalho "pós-fordista” (Belloni, 1999). Tudo isto sem perder de vista os ideais humanistas de formação do cidadão crítico e criativo, capaz de pensar e de mudar o mundo.

Do ponto de vista institucional e político, é preciso saudar com otimismo a criação da Unirede, consórcio que congrega todas as grandes universidades públicas do país, com o objetivo de integrar e otimizar esforços de educação a distância, prioritariamente para a formação de professores em todos os níveis de ensino. A proposta institucional da Unirede, baseada na parceria entre instituições iguais, foi resultado da iniciativa de instituições de ensino e pesquisa e não de uma política imposta pelos organismos oficiais, e talvez por isso apresente maiores possibilidades de assegurar a oferta de atividades efetivas de educação a distância de melhor qualidade com menor custo. 
Recebido em julho de 2001.

Aprovado em dezembro de 2001.

Referências bibliográficas

ALONSO, K.M. "Educação a distância no Brasil: A busca de identidade” In: Preti, O. (Org.), Educação a distância: Inícios e indícios de um percurso. Nead/IE - UFMT. Cuiabá: UFMT, 1996, p. 57-74.

. Novas tecnologias e formação de professores: Um intento de compreensão. Paper, Reunião anual da Anped, Caxambu, 1999.

BABIN, P.; KOULOUMDJIAN, M. Os novos modos de compreender: A geração do audiovisual e do computador. São Paulo: Paulinas, 1989.

BABIN, P. Langage et culture des médias. Paris: Ed. Universitaires, 1991

BELLONI, M.L. O que é mídia-educação. Campinas: Autores Associados, 2001a. (Coleção Polêmicas do Nosso Tempo, 78.

. O ensino a distância na formação de professores: Análise da implantação da TV Escola em Santa Catarina. Relatório de Pesquisa/CNPq, 2001c.

. "Integração das tecnologias de informação e comunicação aos processos educacionais". In: BARRETO, R.G. (Org.), Tecnologias educacionais e educação a distância: Avaliando políticas e práticas, Rio de Janeiro: Quartet, 2001.

. Educaşão a distância. Campinas: Autores Associados,1999.

. Tecnologia e formação de professores. Rumo a uma pedagogia pós-moderna? Educação $\approx$ Sociedade, Campinas: Cedes, 1998, nª 65.

. A mundialização da cultura. Sociedade e Estado, 1994, vol. IX, $\mathrm{n}^{\mathrm{a}} 1 / 2$.

. Educação para a mídia, missão urgente da escola. Comunicaşão \& Sociedade, São Bernardo do Campo, Umesp, 1991, nª 17.

. Escola versus televisão: Uma questão de linguagem. Educação \& Sociedade, Campinas: Cedes, 1995a, nª 52.

- A espetacularização da política e a educação para a cidadania. Perspectiva, 1995b, n⿳亠丷厂 24 . 
- Technologie et éducation: Le système national de televisión éducative au Brésil. Tese de doutorado, Université Paris V, Paris, 1984.

BENAKOUCHE, T. Educação a distância: Uma solução ou um problema? Paper, Reunião anual da Anpocs, Petrópolis, 2000.

CANCLINI, N.G. Consumidores e cidadãos: Conflitos multiculturais da globalização. Rio de Janeiro: Ed. da UFRJ, 1996.

. Culturas hibridas: Tragédias para entrar e sair da modernidade. São Paulo: Edusp, 1998.

. (Org.) Cultura y pospolitica. México: Consejo Nacional para la Cultura y las Artes, 1991.

CARMO, H. Ensino superior a distância. Lisboa: Universidade Aberta, 1998.

DEBORD, G. La société du spectacle. Paris: Buchet/Chastel, 1967 (trad. portuguesa. Lisboa: ed. Mobilis in Mobile, 1991).

DRAIBE, S.M.; PEREZ, J.R.R. O programa TV Escola: Desafios à introdução de novas tecnologias. Cadernos de Pesquisa, São Paulo, Fundação Carlos Chagas, mar. 1999, n- 106, p. 27-50.

FUSARI, M. Multimídias e formação de professores. Paper, Va Endipe, 1994.

GIDDENS, A. As consequiências da modernidade. São Paulo: Editora da Unesp, 1991.

. Modernidade e identidade pessoal. Lisboa: Celta, 1997.

HABERMAS, J. "A técnica e a ciência como ideologia". In: Textos escolhidos. São Paulo: Abril Cultural, 1975. (Coleção Os Pensadores)

JACQUINOT, G. Les genres télévisuels dans l'enseignement. Paris: EADTU, 1990.

LASCH, C. The culture of narci? Londres: Abacus, 1979 (trad. bras.: $A$ cultura do narcisismo. São Paulo: Imago, 1983).

MARCUSE, H. L'homme unidimensionnel. Paris: Minuit, 1968.

MASTERMAN, L. La enseñanza de los medios de comunicación. Madrid: La Torre, 1993. 
MATTELART, A. A comunicaşão-mundo: Histórias das idéias e das estratégias. Petrópolis: Vozes, 1994.

MATTELART, A.; MATTELART, M. Histórias das teorias da comunicação. São Paulo: Loyola, 1997.

NEGROPONTE, N. A sociedade digital. São Paulo: Cia. das Letras, 1995.

PERRIAULT, J. La communication du savior à distance. Paris: Hachette, 1996.

PORCHER, L. L'Ecole parallèle. Paris: Larousse, 1974.

SANTOS, L.G. Desregulagens. São Paulo: Brasiliense, 1981.

SANTOS, B.S. Pela mão de Alice: O social e o político na pósmodernidade. São Paulo: Cortez, 1995.

TOSCHI, Formação de professores e TV Escola. Paper, Reunião anual da Anped, Caxambu, 2000.

TRINDADE, A.R. Introdução à comunicação educacional. Lisboa: Universidade Aberta, 1990. 1990.

Distance education for Europe. Lisboa: Universidade Aberta,

. The salami concept. The proceedings of EADTU - Bourse Conference. Atenas: EADTU, 1991.

YÚDICE,G. "Posmodernidad y capitalismo transnacional en América Latina". In: Canclini, N. (Org.), Cultura y pospolitica. México: Consejo Nacional para la Cultura y las Artes, 1991. 